International Journal of Engineering \& Technology, $7(2.24)(2018) 381-386$
International Journal of Engineering \& Technology
SPC
Website: www.sciencepubco.com/index.php/IJET
Research paper

\title{
A Novel Hybrid Particle Swarm- Multiverse Optimization based Voltage Stability Improvement in IEEE 57 Bus System
}

\author{
P.K.Dhal ${ }^{*}$, K. Ramash Kumar ${ }^{2}$ \\ ${ }^{I}$ Professor, Department of Electrical and Electronics Engineering, Veltech Dr. RR \& Dr.SR University, Chennai, India \\ ${ }^{2}$ Professor, Department of Electrical and Electronics Engineering, Karpagam College of Engineering, Coimbatore, India \\ *Corresponding Author Email: pradyumna.dhal@ rediffmail.com
}

\begin{abstract}
The major role of power system is voltage stability. It is required to plan properly and smooth operation and control. It presents a new approach of voltage stability improvement in IEEE 57 bus system using hybrid algorithm. The hybrid algorithm (PSO-MVO) is combination of PSO which is used for exploitation and MVO used for exploration. It is used in an uncertain environment. The FACTS device as STATCOM is connected in IEEE 57 test system to check for event of voltage stability improvement through power system analysis tool (PSAT) software. Once the ability of system goes through sudden loading, its stability gets affected. It desires compensation to boost voltage from disturbances. The varied operative condition while not used STATCOM in the system, used with STATCOM tuned by PSO-MVO algorithm are measured judge the performance of the projected system. The hybrid PSO-MVO technique is implemented in this paper to solve the proposed problem. The simulation results are obtained by PSAT software for 57 IEEE bus systems. The hybrid algorithm validates its effectiveness compare to individual PSO and MVO algorithm.
\end{abstract}

Keywords: STATCOM; voltage stability;PSAT; PSO-MVO Algorithm.

\section{Introduction}

The modern power industries are growing rapidly from many years. It is required to flow of power in smoothly to fulfill the stain of the consumers. The most functions of those industries unit to provide the electricity to consumers at affordable value with prime quality and reliability. So it's troublesome to control the system firmly. If these systems operate adequately and firmly, then the systems stability is maintained [1] [2]. It is to retain the system stability, it's necessary to preserve the voltage in any respect buses that is closed to value in any respect the days. The power of an influence system is maintained in an appropriate vary relating to as voltage stability [3] [4]. If the voltage moves out an excessive amount from their reset value, it's referred to as voltage collapse. In facility new technologies has established. It is called as flexible AC transmission system (FACTS). The FACTS is fashionable devices that are employed in several aspect like power quality, power stability etc. the idea of this paper, the voltage stability of a multi machine system is analyzed by applying FACTS device called as STATCOM. It is tuned the STATCOM parameter value using hybrid algorithm. The ability of the system is improved [5] [6]. The foremost advantage of the facts device is their fast response to the system's ability recovery. Many authors have solved using intelligent techniques and it is implemented for voltage stability assessment. Recently differential evolutionary algorithm has been implemented.
The differential evolutionary has realized new approach for optimization problem. It's successfully applied in many artificial networks with real optimization problems [7]-[13].

In this paper is highlighted new hybrid PSO-MVO algorithm is novel approach to implement and to solve problem. It is to improve the voltage stability.

\section{Problem Formulation in IEEE 57 Bus}

\section{A. Objective Function}

The basic concept is an objective value of reactive power control. The voltage control is identified based on selection of optimal place which minimize the objective function. The objective is to minimize the fitness value.

Fitness $=\max (\lambda)$ (1)

Where $\lambda$ is loading parameter.

\section{B. Equality Constraints}

The equality constraints are used for power flow in all buses in the system.

i) The power balance equation is

$P_{i}-V_{i} \sum_{j=1}^{N} V_{j}\left[G_{i, j} \cos \delta_{i, j}+B_{i, j} \sin \delta_{i, j}\right]=0 ; i=1,2--(N-1)$

ii) The reactive power equation is

$Q_{i}-V_{i} \sum_{j=1}^{N} V_{j}\left[G_{i, j} \cos \delta_{i, j}+B_{i, j} \sin \delta_{i, j}\right]=0 ; i=1,2--N$

\section{Inequality Constraints}

The inequality constraints are 


$$
\begin{aligned}
& P_{g, i}^{\min } \prec P_{g, i} \prec P_{g, i}^{\max }, i=1,2--N_{\text {generator }} \\
& Q_{g, i}^{\min } \prec Q_{g, i} \prec Q_{g, i}^{\max }, i=1,2--N_{\text {generator }} \\
& V_{g, i}^{\min } \prec V_{g, i} \prec V_{g, i}, i=1,2--N_{\text {load }}
\end{aligned}
$$

\section{Test Analysis IEEE 57 Bus System}

The proposed hybrid has been tested on standard IEEE 57 bus test system using PSAT software. The performance of the STATCOM has evaluated in this system. It is seven generators and forty two loads are connected. The random parameter values are selected and found that bus 31 is very weak bus. It is shown in table 1 . First it is analyzed without STATCOM in this system then with STATCOM tuned by hybrid algorithm. The 57 bus system is shown in figure 1.

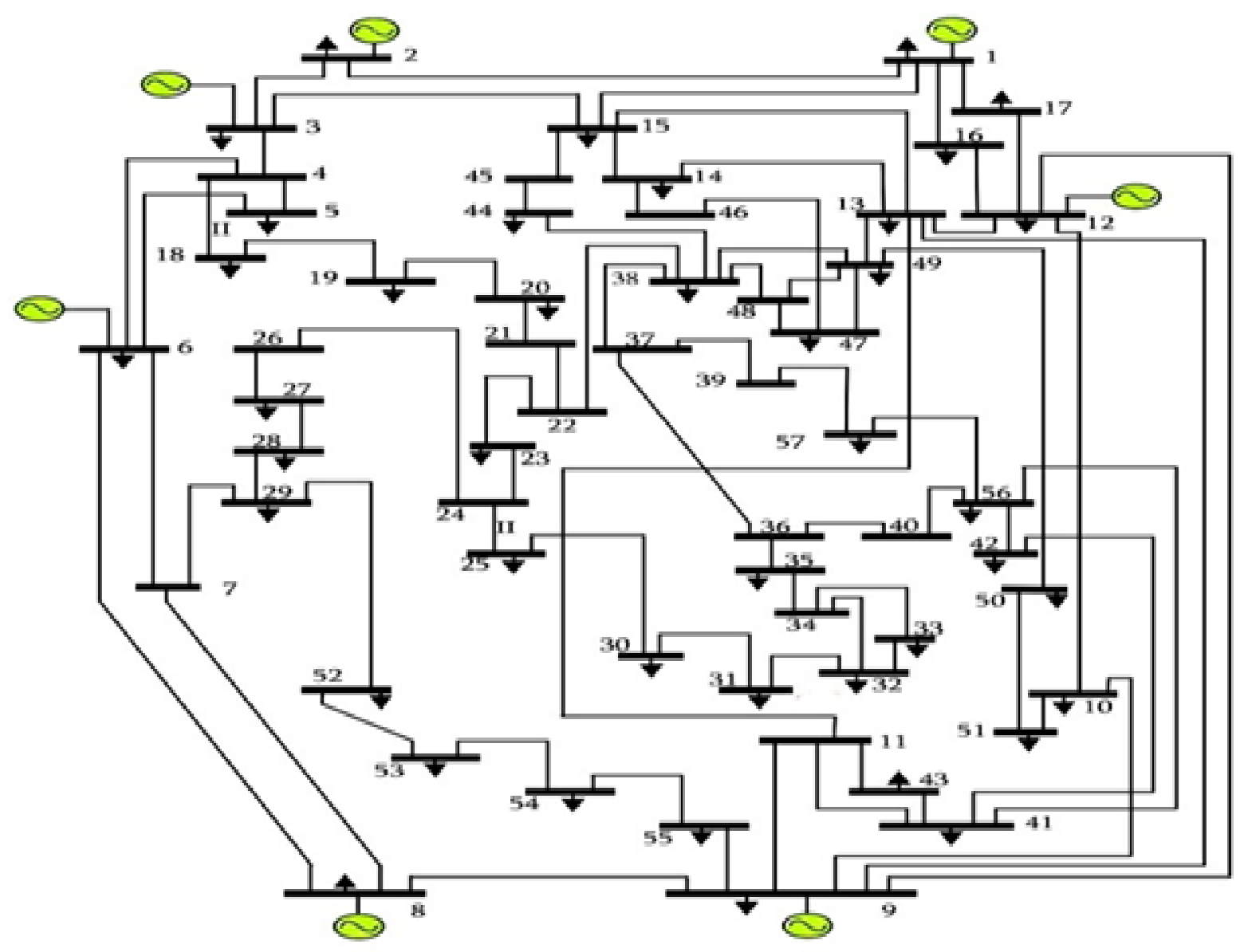

Fig. 1: 57 bus system

\section{Hybrid PSO-MVO Algorithm}

Step 1: to initialize the PSO and STATCOM parameter values Step 2: compute the fitness value

Step 3: to determine $\mathrm{G}_{\text {best }}$ from the $\mathrm{P}_{\text {best }}$ value.

Step 4: updated modify velocity and position value

Step 5: verify the solution whether it is feasible or not

Step 6: if the solution is feasible then verify the iteration calculation

Step 7: if iteration achieves the maximum, stop the procedure

Step 8: if iteration does not reach the maximum value, then continue the process from step2-7.

Step 9: to obtain the optimal value of PSO and it uses the boundary value of MVO algorithm

Step 10: ti initialize the STATCOM parameter values using MVO

Step 11: to create a set of random universes using roulette wheel selection method

Step 12: to calculate the inflation rate i.e fitness value of the universe

Step 13: select the universe value as per inflation rate
Step 14: to update position of the universes

Step 15: if if the convergence criterion is reached then get the results

Step 16: if the convergence criterion is not reached then continue the process from step 2-6 


\section{Proposed Flow Chart in 57 Bus}

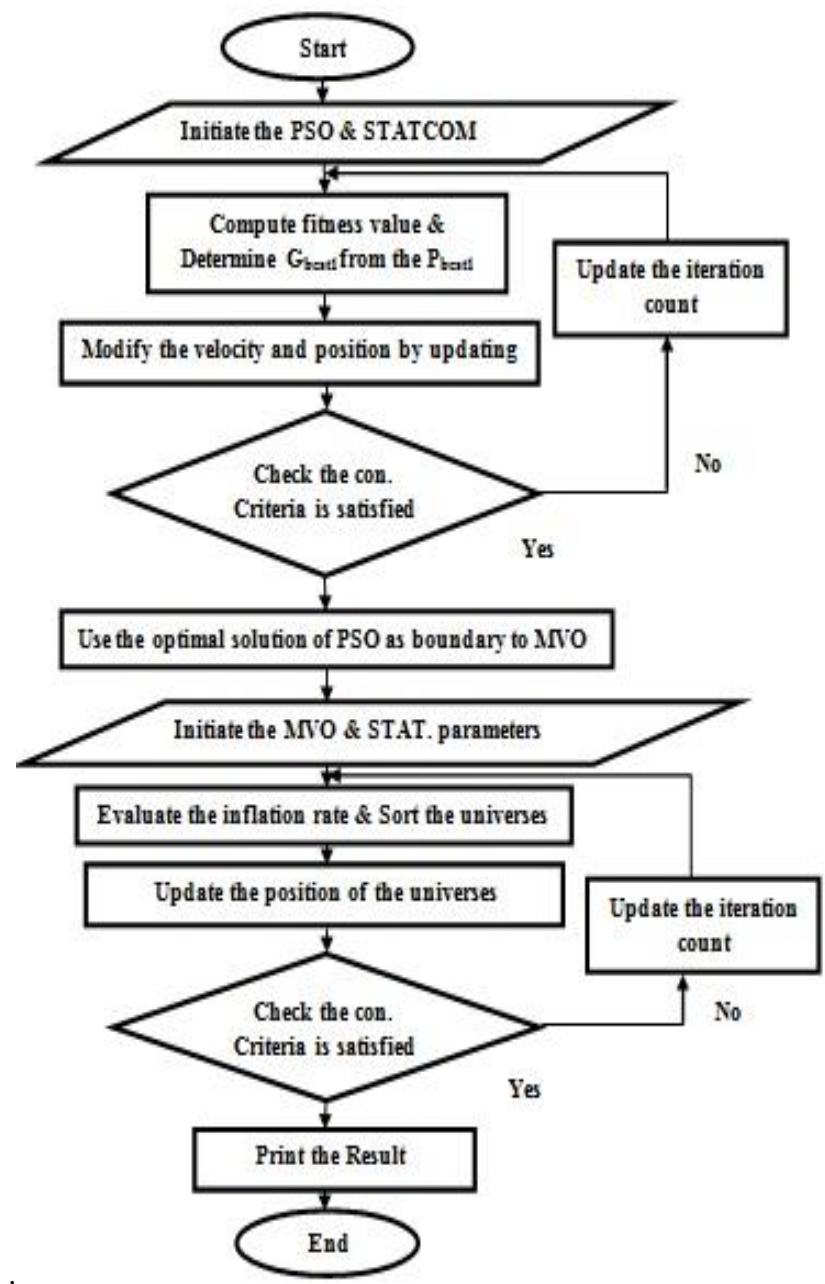

\section{Hybrid PSO-MVO Algorithm in 57 Bus System}

The hybrid PSO-MVO is combination algorithm. It is separated of PSO and MVO. The hybrid algorithm merges the best strength of both PSO in exploitation and MVO is in exploration towards the optimum solution [9] [10]. When it is replaced $P_{\text {best }}$ value of PSO with universe value of MVO as shown in flow chart. The hybrid equation in this system can be written as

$V_{i, j}^{t+1}=V_{i, j}^{t} w+C_{1} R_{1}\left(\right.$ universes $\left.^{t}-X^{t}\right)+C_{2} R_{2}\left(b_{\text {best }}^{t}-X^{t}\right)(7)$

\section{Simulation Result and Discussion}

Here the voltage magnitude profile is shown in figure 3. In this figure at bus 31 is severely affected due to fault. The value is 0.39 p.u without STATCOM. It is shown in figure 3 .

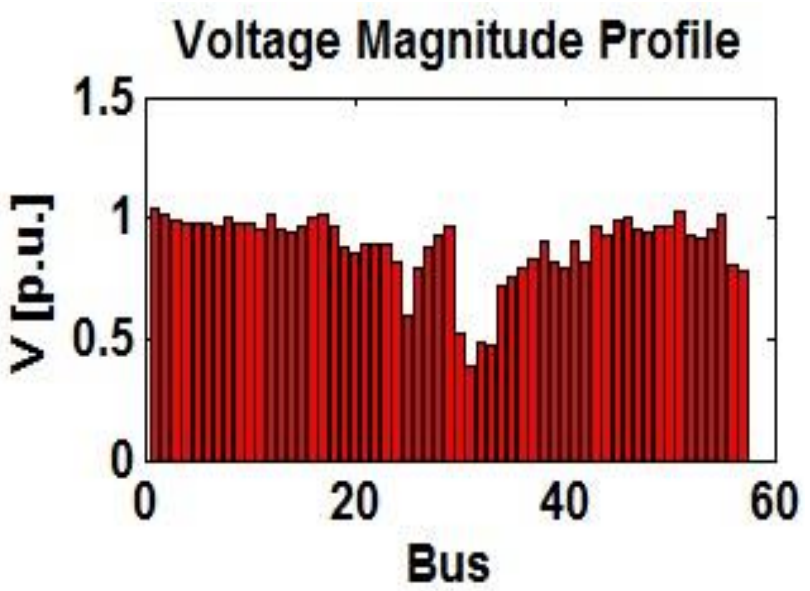

Fig. 3: voltage magnitude of the system without STATCOM

Fig. 2: Proposed flow chart using hybrid system

Table 1: System voltage parameter without STATCOM

\begin{tabular}{|c|c|c|c|c|c|c|}
\hline BUS & $\mathrm{V}$ & Phase & $\mathrm{P}$ generator & Q generator & P Load & Q Load \\
\hline & $\mathrm{pu}$ & $\mathrm{rad}$ & $\mathrm{pu}$ & $\mathrm{pu}$ & $\mathrm{pu}$ & $\mathrm{pu}$ \\
\hline BUS 1 & 1.04 & 0.000 & 6.720 & 1.436 & 0.596 & 0.185 \\
\hline BUS 2 & 1.010 & -0.035 & 0.057 & 0.049 & 0.053 & 0.896 \\
\hline BUS 3 & 0.985 & -0.170 & 0.446 & 0.678 & 0.467 & 0.248 \\
\hline BUS 4 & 0.976 & -0.208 & 0.000 & 0.000 & 0.000 & 0.000 \\
\hline BUS 5 & 0.973 & -0.248 & 0.000 & 0.000 & 0.176 & 0.055 \\
\hline BUS6 & 0.980 & -0.256 & 0.046 & 0.304 & 0.773 & 0.036 \\
\hline BUS7 & 0.966 & -0.252 & 0.000 & 0.000 & 0.000 & 0.000 \\
\hline BUS8 & 1.005 & -0.195 & 4.557 & 0.908 & 1.557 & 0.258 \\
\hline BUS9 & 0.980 & -0.280 & 0.046 & 0.695 & 1.256 & 0.275 \\
\hline BUS10 & 0.971 & -0.306 & 0.000 & 0.000 & 0.073 & 0.036 \\
\hline BUS11 & 0.948 & -0.284 & 0.000 & 0.000 & 0.000 & 0.000 \\
\hline BUS12 & 1.015 & -0.267 & 3.146 & 2.005 & 3.827 & 0.27837 \\
\hline BUS13 & 0.954 & -0.261 & 0.000 & 0.000 & 0.226 & 0.038 \\
\hline BUS14 & 0.936 & -0.248 & 0.000 & 0.000 & 0.128 & 0.069 \\
\hline BUS15 & 0.965 & -0.191 & 0.000 & 0.000 & 0.277 & 0.088 \\
\hline BUS16 & 1.007 & -0.217 & 0.000 & 0.000 & 0.476 & 0.045 \\
\hline BUS17 & 1.011 & -0.126 & 0.000 & 0.000 & 0.443 & 0.096 \\
\hline BUS18 & 0.969 & -0.318 & 0.000 & 0.000 & 0.329 & 0.042 \\
\hline BUS19 & 0.876 & -0.374 & 0.000 & 0.000 & 0.079 & 0.021 \\
\hline BUS20 & 0.854 & -0.377 & 0.000 & 0.000 & 0.046 & 0.026 \\
\hline BUS21 & 0.891 & -0.353 & 0.000 & 0.000 & 0.000 & 0.000 \\
\hline BUS22 & 0.892 & -0.350 & 0.000 & 0.000 & 0.000 & 0.000 \\
\hline BUS23 & 0.886 & -0.352 & 0.000 & 0.000 & 0.120 & 0.059 \\
\hline BUS24 & 0.813 & -0.363 & 0.000 & 0.000 & 0.000 & 0.000 \\
\hline
\end{tabular}




\begin{tabular}{|l|l|l|l|l|c|c|}
\hline BUS25 & 0.601 & -0.722 & 0.000 & 0.000 & 0.109 & 0.025 \\
\hline BUS26 & 0.791 & -0.350 & 0.000 & 0.000 & 0.000 & 0.000 \\
\hline BUS27 & 0.885 & -0.337 & 0.000 & 0.000 & 0.116 & 0.021 \\
\hline BUS28 & 0.931 & -0.321 & 0.000 & 0.000 & 0.103 & 0.061 \\
\hline BUS29 & 0.969 & -0.309 & 0.000 & 0.000 & 0.216 & 0.041 \\
\hline BUS30 & 0.518 & -0.779 & 0.000 & 0.000 & 0.059 & 0.034 \\
\hline BUS31 & 0.389 & -0.908 & 0.000 & 0.000 & 0.115 & 0.067 \\
\hline BUS32 & 0.481 & -0.832 & 0.000 & 0.000 & 0.062 & 0.023 \\
\hline BUS33 & 0.473 & -0.836 & 0.000 & 0.000 & 0.061 & 0.035 \\
\hline BUS34 & 0.718 & -0.376 & 0.000 & 0.000 & 0.000 & 0.000 \\
\hline BUS35 & 0.756 & -0.375 & 0.000 & 0.000 & 0.117 & 0.068 \\
\hline BUS36 & 0.795 & -0.372 & 0.000 & 0.000 & 0.000 & 0.000 \\
\hline BUS37 & 0.824 & -0.367 & 0.000 & 0.000 & 0 & 0 \\
\hline BUS38 & 0.906 & -0.345 & 0.000 & 0.000 & 0.186 & 0.085 \\
\hline BUS39 & 0.820 & -0.369 & 0.000 & 0.000 & 0.000 & 0.000 \\
\hline BUS40 & 0.792 & -0.374 & 0.000 & 0.000 & 0.000 & 0.000 \\
\hline BUS41 & 0.904 & -0.418 & 0.000 & 0.000 & 0.086 & 0.046 \\
\hline BUS42 & 0.822 & -0.460 & 0.000 & 0.000 & 0.128 & 0.082 \\
\hline BUS43 & 0.962 & -0.326 & 0.000 & 0.000 & 0.066 & 0.025 \\
\hline BUS44 & 0.926 & -0.320 & 0.000 & 0.000 & 0.143 & 0.034 \\
\hline BUS45 & 0.987 & -0.253 & 0.000 & 0.000 & 0 & 0 \\
\hline BUS46 & 1.003 & -0.298 & 0.000 & 0.000 & 0 & 0 \\
\hline BUS47 & 0.954 & -0.337 & 0.000 & 0.000 & 0.354 & 0.154 \\
\hline BUS48 & 0.941 & -0.340 & 0.000 & 0.000 & 0.000 & 0.000 \\
\hline BUS49 & 0.967 & -0.348 & 0.000 & 0.000 & 0.2264 & 0.100 \\
\hline BUS50 & 0.967 & -0.356 & 0.000 & 0.000 & 0.233 & $0.12 \mathrm{I}$ \\
\hline BUS51 & 1.026 & -0.334 & 0.000 & 0.000 & 0.237 & 0.091 \\
\hline BUS52 & 0.927 & -0.347 & 0.000 & 0.000 & 0.095 & 0.037 \\
\hline BUS53 & 0.917 & -0.360 & 0.000 & 0.000 & 0.22302 & 0.063 \\
\hline BUS54 & 0.954 & -0.345 & 0.000 & 0.000 & 0.098 & 0.052 \\
\hline BUS55 & 1.020 & -0.318 & 0.000 & 0.000 & 0.114 & 0.049 \\
\hline BUS56 & 0.807 & -0.464 & 0.000 & 0.000 & 0.099 & 0.038 \\
\hline BUS57 & 0.782 & -0.484 & 0.000 & 0.000 & 0.124 & 0.058 \\
\hline & & & & & & \\
\hline
\end{tabular}

In the above table, it found that at bus 31 is affected due to fault or overloaded. So the STATCOM is used at bus 31 system for improvement of voltage stability. It is shown in figure 4 .

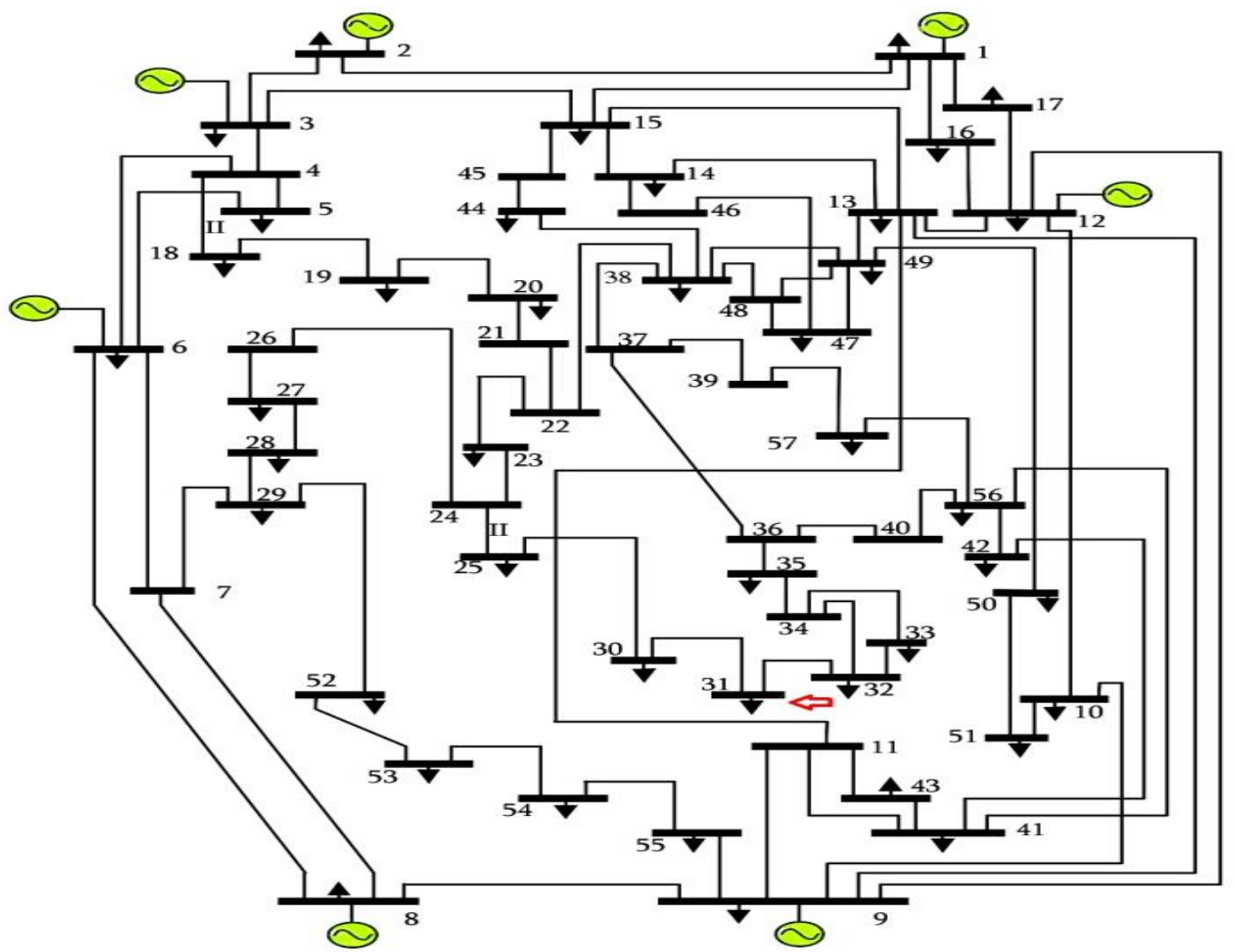

Fig. 4: 57 bus system with STATCOM tuned by hybrid algorithm 
In the above figure 4 shows that the red arrow indicates the place of STATCOM. The STATCOM is tuned by PSO-MVO algorithm as shown in figure 4 and table 2.

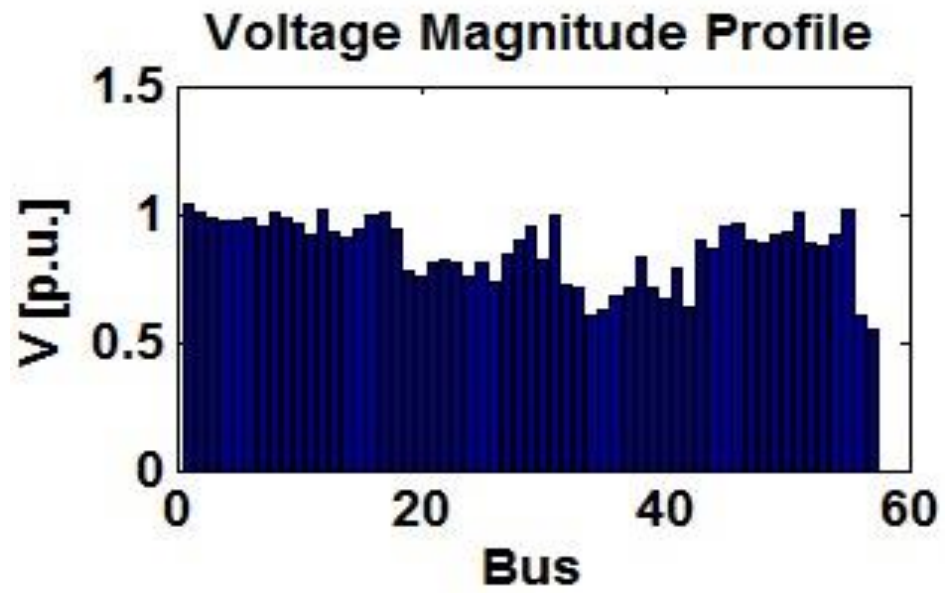

Fig. 5: Voltage profile of the system with STATCOM tuned by PSO-MVO

Table 2: System parameter with STATCOM tuned by PSO-MVO

\begin{tabular}{|c|c|c|c|c|c|c|}
\hline BUS & $\mathrm{V}$ & Phase & $\mathrm{P}$ generator & Q generator & P Load & Q Load \\
\hline & $\mathrm{pu}$ & $\mathrm{rad}$ & $\mathrm{pu}$ & $\mathrm{pu}$ & $\mathrm{pu}$ & $\mathrm{pu}$ \\
\hline BUS 1 & 1.04 & 0 & 9.157 & 1.694 & 0.643 & 0.201 \\
\hline BUS 2 & 1.01 & 0.055 & 0.116 & 0.176 & 0.076 & 0.912 \\
\hline BUS 3 & 0.985 & 0.254 & 0.493 & 1.460 & 0.526 & 0.287 \\
\hline BUS 4 & 0.970 & 0.310 & 0 & 0 & 0 & 0 \\
\hline BUS 5 & 0.969 & 0.374 & 0 & 0 & 0.223 & 0.071 \\
\hline BUS6 & 0.98 & 0.391 & 0.093 & 0.573 & 0.796 & 0.052 \\
\hline BUS7 & 0.955 & 0.408 & 0 & 0 & 0 & 0 \\
\hline BUS8 & 1.005 & 0.340 & 4.616 & 1.103 & 1.616 & 0.297 \\
\hline BUS9 & 0.98 & 0.424 & 0.093 & 1.400 & 1.303 & 0.291 \\
\hline BUS10 & 0.958 & 0.439 & 0 & 0 & 0.096 & 0.052 \\
\hline BUS11 & 0.918 & 0.422 & 0 & 0 & 0 & 0 \\
\hline BUS12 & 1.015 & 0.374 & 3.193 & 2.800 & 3.886 & 0.317 \\
\hline BUS13 & 0.931 & 0.379 & 0 & 0 & 0.273 & 0.054 \\
\hline BUS14 & 0.905 & 0.360 & 0 & 0 & 0.151 & 0.085 \\
\hline BUS15 & 0.943 & 0.278 & 0 & 0 & 0.336 & 0.127 \\
\hline BUS16 & 0.998 & 0.297 & 0 & 0 & 0.523 & 0.061 \\
\hline BUS17 & 1.001 & 0.168 & 0 & 0 & 0.466 & 0.112 \\
\hline BUS18 & 0.937 & 0.460 & 0 & 0 & 0.388 & 0.087 \\
\hline BUS19 & 0.781 & 0.576 & 0 & 0 & 0.126 & 0.037 \\
\hline BUS20 & 0.754 & 0.594 & 0 & 0 & 0.069 & 0.042 \\
\hline BUS21 & 0.810 & 0.551 & 0 & 0 & 0 & 0 \\
\hline BUS22 & 0.816 & 0.548 & 0 & 0 & 0 & 0 \\
\hline BUS23 & 0.809 & 0.557 & 0 & 0 & 0.179 & 0.098 \\
\hline BUS24 & 0.753 & 0.672 & 0 & 0 & 0 & 0 \\
\hline BUS25 & 0.808 & 1.244 & 0 & 0 & 0.156 & 0.024 \\
\hline BUS26 & 0.729 & 0.647 & 0 & 0 & 0 & 0 \\
\hline BUS27 & 0.838 & 0.560 & 0 & 0 & 0.139 & 0.037 \\
\hline BUS28 & 0.895 & 0.519 & 0 & 0 & 0.162 & 0.100 \\
\hline BUS29 & 0.947 & 0.492 & 0 & 0 & 0.263 & 0.05 \\
\hline BUS30 & 0.820 & 1.416 & 0 & 0 & 0.082 & 0.050 \\
\hline BUS31 & 0.994 & 1.732 & 0 & 0 & 0.1746 & -0.945 \\
\hline BUS32 & 0.723 & 1.422 & 0 & 0 & 0.109 & 0.039 \\
\hline BUS33 & 0.716 & 1.424 & 0 & 0 & 0.0846 & 0.0516 \\
\hline BUS34 & 0.597 & 0.731 & 0 & 0 & 0 & 0 \\
\hline BUS35 & 0.629 & 0.674 & 0 & 0 & 0.176 & 0.107 \\
\hline BUS36 & 0.676 & 0.629 & 0 & 0 & 0 & 0 \\
\hline BUS37 & 0.715 & 0.602 & 0 & 0 & 0 & 0 \\
\hline BUS38 & 0.833 & 0.530 & 0 & 0 & 0.233 & 0.101 \\
\hline BUS39 & 0.707 & 0.602 & 0 & 0 & 0 & 0 \\
\hline BUS40 & 0.670 & 0.631 & 0 & 0 & 0 & 0 \\
\hline
\end{tabular}




\begin{tabular}{|c|c|c|c|c|c|c|}
\hline BUS41 & 0.786 & 0.672 & 0 & 0 & 0.109 & 0.062 \\
\hline BUS42 & 0.630 & 0.771 & 0 & 0 & 0.187 & 0.121 \\
\hline BUS43 & 0.902 & 0.495 & 0 & 0 & 0.113 & 0.041 \\
\hline BUS44 & 0.862 & 0.483 & 0 & 0 & 0.166 & 0.050 \\
\hline BUS45 & 0.951 & 0.374 & 0 & 0 & 0 & 0 \\
\hline BUS46 & 0.960 & 0.435 & 0 & 0 & 0 & 0 \\
\hline BUS47 & 0.898 & 0.498 & 0 & 0 & 0.413 & 0.193 \\
\hline BUS48 & 0.880 & 0.507 & 0 & 0 & 0 & 0 \\
\hline BUS49 & 0.919 & 0.509 & 0 & 0 & 0.273 & 0.116 \\
\hline BUS50 & 0.924 & 0.513 & 0 & 0 & 0.256 & 0.137 \\
\hline BUS51 & 1.006 & 0.478 & 0 & 0 & 0.296 & 0.130 \\
\hline BUS52 & 0.887 & 0.535 & 0 & 0 & 0.142 & 0.053 \\
\hline BUS53 & 0.873 & 0.546 & 0 & 0 & 0.246 & 0.084 \\
\hline BUS54 & 0.917 & 0.521 & 0 & 0 & 0.157 & 0.091 \\
\hline BUS55 & 1.011 & 0.478 & 0 & 0 & 0.161 & 0.065 \\
\hline BUS56 & 0.607 & 0.792 & 0 & 0 & 0.122 & 0.054 \\
\hline BUS57 & 0.553 & 0.857 & 0 & 0 & 0.183 & 0.097 \\
\hline
\end{tabular}

\section{Conclusion}

The hybrid PSO-MVO algorithm is successfully applied in IEEE 57 bus test system to solve voltage stability problem. It is intelligently applied to solve this problem. The voltage stability of the system with STATCOM device is investigated through the continuation power flow simulation. It is found that the hybrid optimization technique can be effectively utilized. It satisfies all the equality and inequality constraints value of the system. The voltage of the system is achieved from $0.39 \mathrm{pu}$ value to $099 \mathrm{pu}$ value.

\section{References}

[1] K.Karthikeyan, P.K.Dhal," Multilevel optimization technique based voltage stability through continuation power flow in IEEE 57 bus', Energy Procedia, Elsevier 117(2017), pp.583-591.

[2] Pradeep Jangir,sidharth A, parmar, indrajit $\mathrm{N}$ trivedi, R.H. Bhesdadiya," A novel hybrid particle swarm optimizer with multiverse optimizer for global numerical optimization and optimal reactive power dispatch problem', Engineering science and technology an international journal, vol 20. Issue 2, pp.570586, 2017.

[3] Anwar S, Siddiqui, Tanmoy Deb, "voltage stability improvement using STATCOM and SVC', International journal of computer applications, vol.88, no.14, 2014.

[4] R. benabid, M.Boudour, M.A. Abido, ${ }^{\text {e }}$ optimal location and setting of SVC and TCSC devices using nondomonated sorting particle swarm optimization", Electic power systems research 79, pp.1668-1677, 2009.

[5] Kessel P, Glavitsch $\mathrm{H}$, Estimating the voltage stability of power systems', IEEE Trans power apparatus system, 1986, 1: 346354.

[6] Alsac O, scott B, " optimal load flow with steady state security", IEEE Trans. On power apparatus system 1974, pp.187-202.

[7] Van Cutsem $T$, "A method to compute reactive power margin with respect to voltage collapse', IEEE Trans. Power system 1991, 6: 145-156.

[8] Grudinin N," Reactive power optimization using successive quadratic programming method", Ieee Trans. Power system 1998, 13: 1219-1225.

[9] Sagarika, T.R.Jyothsna, "e Tunning of PSO algorithm for single machine and multi machine power system using STATCOM controller', international journal of engineering and technology, vol 2, issue 4, pp.175-182, 2015.

[10] K.Karthikeyan, P.K.Dhal, “ Transient stability enhancement by optimal location and tuning of STATCOM using PSO', Procedia technology, 2015.

[11] K. Ramash Kumar, D.Kalyankumar, DR.V.Kirbakaran" An Hybrid Multi level Inverter Based DSTATCOM Control, Majlesi Journal of Electrical Engineering, Vol. 5. No. 2, pp. 17-22, June 2011, ISSN: 0000-0388.

[12] P. Sivakumar, V. Rajasekaran, K. Ramash Kumar, "Investigation of Intelligent Controllers for Varibale Speeed PFC Buck-Boost
Rectifier Fed BLDC Motor Drive," Journal of Electrical Engineering (Romania), Vol.17, No.4, 2017, pp. 459-471.

[13] K. Ramash Kumar,'Implementation of Sliding Mode Controller plus Proportional Integral Controller for Negative Output Elementary Boost Converter," Alexandria Engineering Journal (Elsevier), 2016, Vol. 55, No. 2, pp. 1429-1445.

[14] T. Padmapriya and V.Saminadan, "Improving Performance of Downlink LTE-Advanced Networks Using Advanced Networks Using Advanced feedback Mechanisms and SINR Model", International Conference on Emerging Technology (ICET), vol.7, no.1, pp: 93, March 2014.

[15] S.V. Manikanthan , T. Padmapriya "An enhanced distributed evolved node-b architecture in $5 \mathrm{G}$ tele-communications network" International Journal of Engineering \& Technology (UAE), Vol 7 Issues No (2.8) (2018) 248-254.March2018.

[16] S.V.Manikanthan and K.Baskaran "Low Cost VLSI Design Implementation of Sorting Network for ACSFD in Wireless Sensor Network", CiiT International Journal of Programmable Device Circuits and Systems,Print: ISSN 0974 - 973X \& Online: ISSN 0974 - 9624, Issue : November 2011, PDCS112011008. 